\title{
Stakeholder expectations of the business rescue plan from a South African perspective
}

\author{
Wesley Rosslyn-Smith \\ Wesley.Rosslyn-Smith@up.ac.za
}

Marius Pretorius

Marius.pretorius@up.ac.za

\author{
University of Pretoria \\ South Africa
}

\begin{abstract}
Background: A business rescue plan has to comply with a new and vague set of obligations regulated by South African legislation. Expectations of the plan are largely unknown, yet crucial in determining compliance. Establishing an effective benchmark for the plan is essential for the growth and success of the industry.

Purpose: The study set out to answer these questions: What are the most crucial elements needed to fill the gap between the specifics of the Companies Act (2008) and the further elements needed to meet the plan's primary objective of providing adequate information to stakeholders? What are the international principles applicable to rehabilitation plans and what elements underpin them?

Method: Thirteen industry experts were selected and interviewed to identify the most crucial elements of the business rescue plan. Sampling was a combination of convenience and purposive sampling. Data collection obtained data on subjects' opinions, rankings, agreement and ratings.

Results: The study was able to confirm that there is indeed a gap between the mandatory elements prescribed in section 150(2) and the provision of sufficient information required by section 150(1) of the Companies Act No. 71 of 2008. The survey revealed that in the subjects' expert opinion, the international principles are applicable to the business rescue plan.
\end{abstract}


Conclusion: The crucial elements of the rehabilitation plan selected by the experts offer insight and clarity in terms of what is expected of the plan.

Key words: Business Rescue, Companies Act, Business Plans, Measurement, Insolvency, Turnaround, Reorganisation

\section{INTRODUCTION}

"In any case you mustn't confuse a single failure with a final defeat." - F. Scott Fitzgerald, Tender Is the Night

Corporate reorganisation, a subset of insolvency procedures, has to a large extent been moulded by developed economies. International insolvency frameworks are partially unaccustomed to the realities present in emerging markets. While reorganisation may take a number of different forms, the benefits are increasingly accepted, and insolvency laws in several countries include provisions for formal reorganisation proceedings. South Africa has through the promulgation of the Companies Act No. 71 of 2008 ("the act") in April 2009, effective on 1 May 2011, joined the international community in adopting a modern reorganisation regime. Chapter 6 of the act, which deals with business rescue, is the generic term billed to define and instruct formal reorganisational proceedings.

'Business rescue' proceedings are designed to offer a financially distressed debtor the necessary breathing space to recover from its temporary liquidity difficulties and, if necessary, provide it with an opportunity to restructure its debt and its relations with creditors in order to continue with its business activities. The act requires an s131 court order or an ss129 and ss130 company resolution to commence proceedings, followed by the appointment of a business rescue practitioner ('practitioner'). The practitioner is expected to affirm the appointment if he or she believes there is a reasonable prospect of rescuing the company and 
it is within his or her ability to do so. The management of the company's affairs, business and property is then placed under the temporary supervision of the practitioner. A temporary moratorium on the rights of claimants against the company is immediately initiated.

The focus of proceedings is then shifted to the development and implementation, if approved, of a plan to rescue the company. Twenty-five business days, with exception, are awarded to the practitioner after appointment to construct and publish a viable business plan. The objective of the plan is to detail the mechanisms and outcomes to be used so that the company can overcome its financial difficulties and resume normal commercial operations on a solvent basis. In the event that this is not possible, the implementation of the proposal must result in a better return for the company's creditors or shareholders than would result from the immediate liquidation of the company. S150 of the act prescribes the content to be presented in the business rescue plan. The overarching mandate is to provide sufficient information to the affected parties for them to reach a decision regarding its adoption. S150(2) details specific elements to be included in the document; however, this only results in the bare minimum required for compliance, and it is generally accepted that the plan should go beyond it.

\section{KEY FOCUS OF THE STUDY}

This study aims to explore what experts in the field of business rescue regard as crucial elements of a business rescue plan. The research focuses on clarifying the unspecified gap (void) left when the plan is expected to go beyond the detailed specifics of s150(2) (Republic of South Africa, 2008), in order to fulfil its primary objective of providing adequate information to the affected parties. International principles derived from similar regimes are evaluated to ascertain if they are relevant to business rescue. The principles are discussed, as well as ways to better meet them. Fundamental elements are scrutinised and explored, to gather insight into how the industry can evolve. This study does not intend to 
formulate a template for the rescue plan, but rather to initiate a school of thought as to how the plan should behave, and expose contentious issues currently being faced.

\section{LITERATURE}

The introduction of Chapter 6 of the new Companies Act, No. 71 of 2008 ("the act") has brought to light a new era for South African insolvency in the form of business rescue. While its predecessor, judicial management of the Companies Act of 1926, was at first a pioneer, over time it became outdated and ineffective (Westbrook, 2010:122, Kloppers, 1999:417). Chapter 6, however, aims to reverse that by implementing a more efficient and modern recovery mechanism for financially distressed companies in a way that balances the rights of affected parties (Du Toit, 2012:1). This bold piece of legislature is aimed at improving national unemployment and offering better rehabilitation techniques to ailing businesses (Johnson \& Meyerman, 2010:8). The judicial management process had no statutory provision for the development or drafting of a rescue plan (Loubser, 2010:41). One of the major innovations of business rescue, however, is the prerequisite that a rescue plan must be prepared in order to illustrate how the rehabilitation of the company will be achieved. The absence of this requirement is believed to be one of the reasons why judicial management rarely led to a successful rescue (Loubser, 2010:115).

A large body of literature - starting from the work by Dolan (1983:26), Balgobin and Pandit (2001:304) and others (Westbrook, 2010:151, World Bank, 2005:6, INSOL International, 2000:26) - has drawn attention to the importance of the rescue plan in both formal and informal turnaround situations. The objective of the information-gathering, due diligence and evaluation processes provided for by legislature is to allow the relevant stakeholders to evaluate the debtor's position and make the best decision (INSOL International, 2000:26). 
Recent research into business rescue has revealed numerous challenges facing the industry. Le Roux and Duncan (2013:69) identified the fact that the majority of creditors involved in business rescue proceedings had little to no knowledge of the regime and what it involved. Their research indicates that a poor expectation of the plan stems from a lack of understanding and experience within the industry. Research conducted by Pretorius (2013a:13) into the competencies required by a business rescue practitioner revealed that most entailed critical elements of the business plan. This reiterated that a direct correlation between the practitioner's ability to draft the plan and the effectiveness of the rescue. A preceding study (Pretorius \& Holtzhauzen, 2008:103) found that legitimacy, resource scarcity, leadership capacity, strategy options, data integrity and integration were the most relevant assets of practitioners.

Research makes it clear that the practitioner requires a defined skill set to design, publish and implement the plan successfully. Furthermore, correlation between the needs and expectations of the affected parties and the content published in the plan is crucial to its eventual adoption (United Nations, 2005:190).

The act details the procedural guidelines to be followed throughout the business rescue proceedings. Strict accordance with the act must be followed from the onset of proceedings, by both the directors and the affected parties, until substantial implementation is reached.

After publication of the plan, the practitioner must convene and preside over a meeting of creditors and any other bearers of voting power to consider the proposed plan (Republic of South Africa, 2008:s151(1)). The document must provide sufficient information to enable the parties to make an informed decision, requiring only a 75 percent majority in attendance of the meeting to be approved (Republic of South Africa, 2008:s152(2)a). The act defines an affected party as a shareholder, creditor, employee (or their representative) or a registered trade 
union representing employees of the company. Affected persons have various rights throughout the business rescue process (Republic of South Africa, 2008:s128(1)(a)). Section 7(k) (Republic of South Africa, 2008) of the act extends the targeted audience by "providing for the efficient rescue and recovery of financially distressed companies, in a manner that balances the rights and interests of all relevant stakeholders". While not all stakeholders of the company may be awarded voting rights, they are implicitly included in proceedings by the act.

\section{International principles for the business rescue plan}

Five international principles were identified by Pretorius and Rosslyn-Smith (2014 forthcoming) as directives for the implementation of the business rescue plan. That research entailed evaluating the expectations held by four prominent regimes, namely those of the United States, United Kingdom, Canada and Australia. The researchers examined expectations of the reorganisational plans of these regimes, in the context of their insolvency frameworks. The plan was found to serve as a tool for feasibility declaration, a medium of communication, an enabler of transparency, a contractual obligation and finally to assist decision making for attracting post-commencement finance (PCF). These principles are the comparative benchmarks used for this study and are therefore briefly discussed as follows:

The first principle calls for the business rescue plan to serve as a tool for feasibility declaration. The outcome of the plan is reliant on what is feasible; that is, based on the facts, circumstances and practical assumptions, the plan involves a strategy intended to rehabilitate the company and in so doing offer creditors a better return. It provides a clear reference point during the rapid and often confusing changes common during the rescue process. It also safeguards key resources by clearly acknowledging and preserving those on which the strategy for recovery is based (Balgobin \& Pandit, 2001:14). This principle requires the plan to explain how the business will remain operational, be 
successfully reorganised and how implementation of the plan will be supervised, with reference to a timeframe detailing its execution.

The second principle entails the business rescue plan's serving as a medium of communication. Balgobin and Pandit (2001:314) maintain that a rescue plan which is communicated properly will help clarify and safeguard critical resources. Kow (2004:242) talks about a 'communications plan' and explains that the plan should make clear why the company is undergoing the turnaround effort, how it will do it, what the employees can expect during the process, and what the company will gain from the effort. Effective communication is statutorily required in order to adequately inform creditors. Furthermore, the plan must persuade key stakeholders to believe in the future potential of the business by building credibility, confidence and trust in the future prospects of the business. Until the plan is published, the majority of the stakeholders may be oblivious to the turnaround strategies or the reasons for distress. This principle makes the point that though the plan is usually heavily laden with legal jargon, the language used should be reconsidered carefully in light of these aspects.

The next principle requires the business rescue plan to serve its contractual obligations. Since the plan is in essence a binding contract, it enables various remedies to assist with the rehabilitation. The practitioner, creditors and possibly other external parties may also be bound by the terms of the plan and, by virtue of their position, remain responsible for its implementation. The parties are contractually bound until the business rescue plan has been substantially implemented. This requires that the plan encompass all relevant information, not only for decision-making purposes but to prevent legal action against the process and the practitioner. The contractual nature of the plan has far-reaching consequences that ought to be contemplated.

The fourth principle calls for the business rescue plan to serve as an enabler of transparency. International expectations require that the plan be transparent 
and predictable. The rationale is to enable potential lenders and creditors to understand how proceedings function and to assess the risk accompanying their position as a creditor in the event of rehabilitation. Success in this regard will promote stability in commercial relations and nurture lending and investment at lower risk premiums. Transparency and predictability will in addition allow creditors to clarify priorities, prevent arguments by offering a backdrop against which relative rights and risks can be assessed, and help define the limits of any disagreement (United Nations, 2012:13). Vague and loosely designed plans could undermine not only the confidence of all participants but also their willingness to make investment decisions. As far as possible, the plan should clearly indicate all provisions that may affect the rights of creditors or alter their risk profile.

Finally, the last expectation identified is that the business rescue plan should attract and secure PCF. To ensure the continued operation of the distressed entity after the commencement of formal proceedings, it is critical to obtain a source of new finance as soon as possible. The premise of post-commencement funding extends from short-term recovery needs to the long-term strategy of the reorganisational plan (United Nations, 2005:113). The reorganisational plan is expected to address any sort of PCF that has been approved or recommended. The plan should set out the effects of funding on the business and on the interests of any affected party. The pros and cons of any financial arrangement should be clearly addressed for objective evaluation by affected parties. Incentivised tools within insolvency legislature are aimed at encouraging PCF (du Preez, 2012:36). This may afford the ability to authorise super-priority status to credit or debt incurred. Such actions inevitably have far-reaching consequences. Where the plan is concerned, it needs to explicitly elaborate upon the reason for and use of such tools offered by formal reorganisation.

Literature on the business rescue plan remains limited, and most of the aspects of the plan have remained uncontested in South African courts at the time of this 
review. It is not the intention of this study to incorporate the views of the court, though the researchers are cognisant of the latest judgments relating to the business rescue plan to date.

\section{RESEARCH OBJECTIVES AND QUESTIONS}

International research, described in the literature review, has demonstrated that business rescue legislation encourages the plan to exceed the rigid conditions prescribed in the act in order to be successfully adopted. This study aims to find substantive evidence that additional expectations of the plan exist. Following the identification of key international expectations (Pretorius \& Rosslyn-Smith, 2014 forthcoming), the opinion of key industry experts would determine whether these principles are applicable to the South African regime, and to what extent they should apply. Therefore, the following investigative questions are presented:

- What are the expectations of a business rescue plan from a local perspective?

- Are they in line with the international principles?

- How far should these expectations be explored?

\section{THE POTENTIAL VALUE-ADD OF THE STUDY}

The study has embarked on a new aspect of reorganisation: to explore and detail the workings of the business rescue plan as part of a formal turnaround process. Limited literature has discussed the intricacies of the plan and its impact on proceedings. Though this study by no means aims to completely define the plan, it does hope to initiate further exploration into the various aspects it presents. Beyond that, this study is intended to assist practitioners by better aligning their content with the expectations of their targeted audience; provide creditors and other affected parties with clearer expectations; and finally offer the regulator and other institutions a means to better evaluate the plan. 


\section{RESEARCH DESIGN AND METHODOLOGY}

\section{Research Approach}

An exploratory analysis was applied, with confirmatory and descriptive elements aimed at better understanding a new phenomenon. This pertains to expectations associated with a business rescue plan, from the perspectives of professionals proficient in the field of business rescue (Saunders \& Lewis, 2012). Analysis of pre-existing rescue plans identified a disparity between the expectations held by decision makers and the content published. A literature review of international benchmarks further revealed areas beyond the detail of the act, suggesting that there were additional elements the plan should satisfy. The fact that local literature was limited suggested that a qualitative research approach be used to explore the phenomenon in more depth (Cooper \& Schindler, 2008:140).The study aimed to use these questions simultaneously to guide the research.

Table 1 Research design components (modified from Yin (2003:21))

\begin{tabular}{|c|c|}
\hline Component & Description \\
\hline Problem & $\begin{array}{l}\text { There are no clear guidelines for what should be included in a business } \\
\text { rescue plan. }\end{array}$ \\
\hline $\begin{array}{l}\text { Research question } \\
\text { / problem }\end{array}$ & $\begin{array}{l}\text { What are the expectations of the business rescue plan from a South } \\
\text { African perspective? }\end{array}$ \\
\hline Context & Turnaround and business rescue \\
\hline Propositions & $\begin{array}{l}\text { Proposition \#1: There are expectations that extend beyond the } \\
\text { prerequisites of section 150(2)a of the Companies Act No. } 71 \text { of } \\
2008 . \\
\text { Proposition \#2: The expectations of the business rescue plan fall in } \\
\text { line with international principles. } \\
\text { - } \quad \text { Proposition \#3: Key expectations can be identified and defined. }\end{array}$ \\
\hline $\begin{array}{l}\text { Phenomenon } \\
\text { investigated }\end{array}$ & $\begin{array}{l}\text { Primary: Expectations of experts in the field of business rescue. } \\
\text { Secondary: Five international principles of the rescue plan (benchmark) }\end{array}$ \\
\hline Units of & Thirteen senior experts from six key industries influencing business \\
\hline
\end{tabular}




\begin{tabular}{|l|l|}
\hline observation & \multicolumn{1}{|c|}{$\begin{array}{c}\text { rescue in South Africa. } \\
\text { Chapter } 6 \text { of the Companies Act No. } 71 \text { of } 2008\end{array}$} \\
\hline Method & Specialist and expert interviews \\
\hline $\begin{array}{l}\text { Logic linking the } \\
\text { data to the } \\
\text { propositions }\end{array}$ & $\begin{array}{l}\text { Industry experts are tasked to understand and evaluate the plan. The } \\
\text { chosen individuals are all final decision makers, best suited to offer critical } \\
\text { insights into the content of the plan in order to perform their task effectively. } \\
\text { Experts are poised to offer the best objective expectations of the plan. }\end{array}$ \\
\hline $\begin{array}{l}\text { Criteria for } \\
\text { interpreting the } \\
\text { findings }\end{array}$ & $\begin{array}{l}\text { The expectations identified by industry experts } \\
\text { - Experts' support of the international principles }\end{array}$ \\
\hline
\end{tabular}

\section{Key Scientific Beliefs of the Researchers}

To answer the above questions, the researchers were aware of their own methodological values, beliefs and particular philosophical assumptions. These assumptions could influence the way in which the research was conducted and are stated to understand the 'intellectual climate' in which the research was undertaken.

\section{Ontological Positions}

Ontological positions comprise researcher A and B's views on the nature and essence of the research reality. Both researchers are objective realists who believe that knowledge comes from facts associated with real-life cases and their context. Where either researcher found repeated mentions of practices and praxis, they could "generalise" them. The researchers aimed to maintain a critical view of each regime and interpret legal works from an international insolvency perspective. The interest focused on understanding and describing a set of principles that could confirm the international perspective on the expectations of a rescue plan for South Africa (Saunders, Lewis \& Thornhill, 2009:110). 


\section{Epistemological Positions}

In attempting to answer the research questions, the researchers were aware of their own individual methodological values, beliefs and philosophical assumptions. These assumptions could influence how the research was conducted and are stated in order to understand the 'intellectual climate' in which the research was conducted. The theory of knowledge (epistemology) of the researchers describes how they are able to discover underlying principles about social phenomena and how one can demonstrate knowledge. The researchers have personal experience in the context of business rescue. At the same time, as an academic and turnaround consultant and as a post graduate student, they have a preference for factual directives.

\section{Research setting and background}

The researcher conducted 13 interviews with high-level experts, covering six discrete but critical professions pertaining to the field of business rescue. Subjects with practical experience and knowledge in the field of business rescue were chosen. The six disciplines included practitioners, lawyers, creditors, banking representatives, distressed venture capitalists and government officials associated with the regulator. A semi-structured interview format was chosen, by conducting non-standardised, one-to-one interviews with subjects (Saunders et al., 2009:320). During the interview, subjects were requested to reflect on their understanding of the plan and what they expected from it. Following an openended discussion, the subjects were led with a protocol aligned with the international principles mentioned above. Both open and closed questions were used to improve understanding of the results (Blumberg, Cooper \& Schindler, 2008:143).

\section{Sampling}

The research question required experienced and qualified professionals to ascertain holistic views of the plan in its various forms. Subjects with significant exposure to multiple types of plan were needed. The business rescue environment offered a limited population of professionals meeting this criterion. 
Using these characteristics/criteria, a judgement-sampling technique was applied. The purposive selection of subjects considered peer recommendations, socioeconomic status, extent of knowledge of insolvency, and level of exposure to decision-making experience in the business-rescue environment. The purposive sample size for the research was determined after theoretical saturation arose. The ideal number of twelve interviews sufficed to achieve this milestone (Guest, 2006:59). Represented in the sample were practitioners, bankers, legal specialists, potential government investors and creditors.

Table 2 Interview Statistics

\begin{tabular}{|l|l|}
\hline Description & Quantity \\
\hline Total number of interviews & 13 \\
\hline Number of disciplines covered & 6 \\
\hline Total length of all interviews & 854.15 minutes \\
\hline Average length of interviews & 65.7 minutes \\
\hline Shortest interview & 45.54 minutes \\
\hline Longest interview & 79.55 minutes \\
\hline
\end{tabular}

\section{Data analysis}

Descriptive data from the interviews was collected and disseminated into single thought elements. Salient themes were then identified and categorised into the appropriate underlying international principle (Fossey, Harvey, McDermott \& Davidson, 2002:728, Marshall \& Rossman, 2006:158). Discovery-focused techniques aim to establish patterns and connections between elements of data require the use of inductive reasoning (Leedy \& Ormrod, 2001:33, Fossey et al., 2002:728). The interviews, direct observations and physical artefacts were converged to assist with the interpretation (Yin, 2003:89). 


\section{FINDINGS}

Figure 1 presents a framework based on the findings of this research.

It shows at its centre the five international guideline principles associated with turnaround plans for which literature does exist. On the outside it shows the contributions of this research, populated with specific elements covering the different expectations of the subjects as categorised by the researchers. Each element is expanded on in detail below.

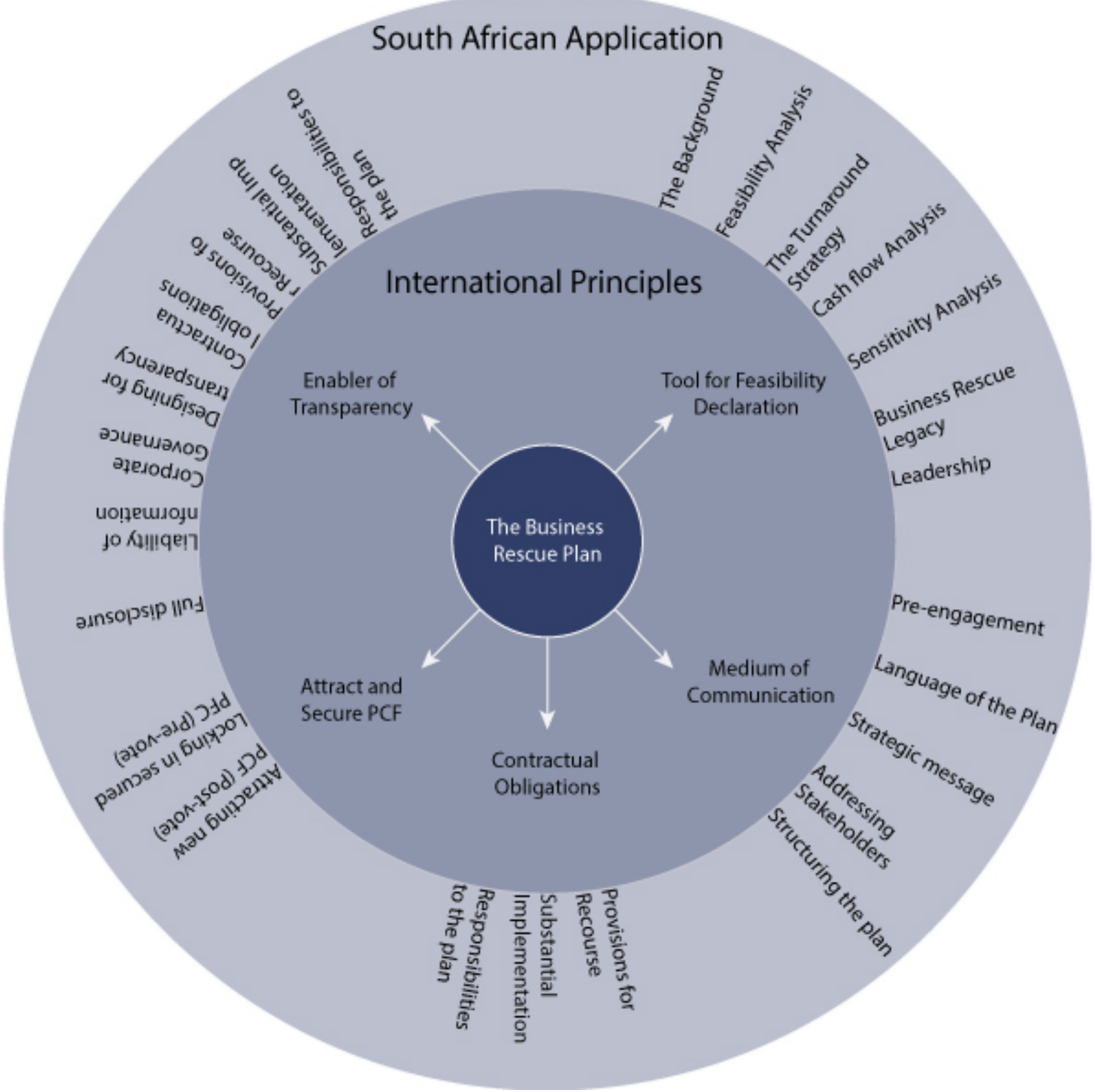

Figure 1 Conceptual framework of the rescue plan in South Africa 


\section{DISCUSSION OF FINDINGS}

The research uncovered a number of interesting results, while supporting general beliefs as to the nature of the plan and the direction it should follow. Most promising is that all the subjects interviewed supported all five principles and could align their expectations in accordance with them. Generally accepted expectations surfaced within each principle, indicating that more often than not the views of the subjects were in line with one another. These expectations are explored in more detail below, in combination with any outliers that accompanied them.

\section{Business rescue plan as a feasibility declaration}

The act allows for two distinct types of a plan to be pursued by the practitioner. The first, and notably the most controversial, is a plan aimed solely at achieving a better return, perhaps more accurately referred to as a controlled wind-down proposal. Here the objective of the practitioner is simply to attain a higher return for creditors than would result from a liquidation procedure. This process in essence is simply the disposal of the company's assets, and differs only marginally from liquidation, justifying the use of terminology like: "soft, glorified, informal and disguised" liquidation. The plan is somewhat clinical and minimal in nature and offers no means of salvaging the company as an ongoing concern. Subjects offered little insight into a better return plan (wind-down proposal). The general consensus was that bare minimum compliance was needed, with strong reasoning by the practitioner as to why this direction had been chosen. The need for a feasibility declaration in such a plan would prove redundant - unless to substantiate the view that pursuing a turnaround strategy would be unviable. However, the viability analysis is still relevant, but as viability is found negative it is not included in the plan.

The second, and more indicative of business rescue, is that of a turnaround plan. Here the objective centres on saving the entity as a whole and deploys various strategies to do so. The second of the two options is significantly more complex. 
One respondent suggests this is where a shred of 'personality' is usually required. While both options (better return or restructuring) are suitable forms of rescue plan (by law), they differ significantly with regards to their expectations. Support for the elements associated with the feasibility declaration by the subjects is shown in Figure 2 and discussed in order of process rather than order of support.

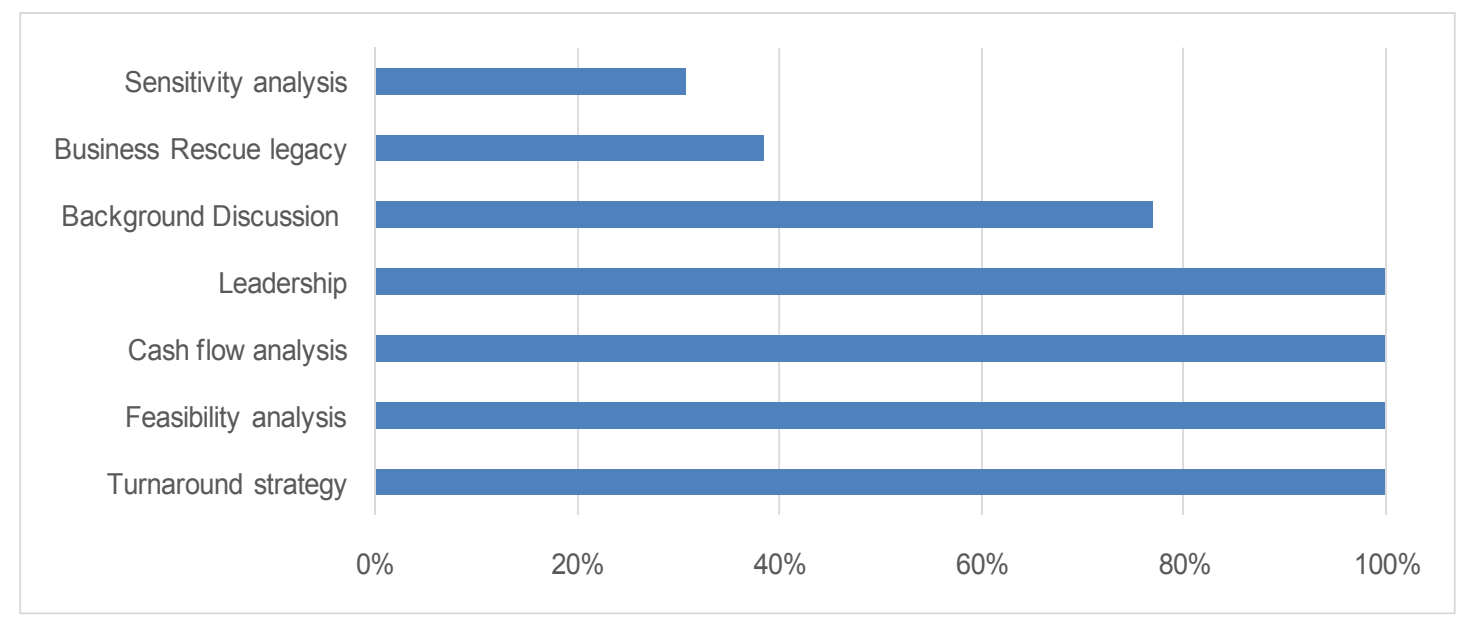

Figure 2 Relative support by subjects for elements of the feasibility declaration

\section{The Background}

The turnaround plan, which is better known as a reorganisational plan within the international community, attracted significantly greater interest from the subjects. While the act already encompasses a large majority of the expectations identified, a number of additional elements were revealed. In-depth detail of the background of the business was deemed essential, offering insight and context to the situation. This also assisted in building credibility among parties already familiar with the company's affairs. Such detail was emphasised by a number of subjects, suggesting the background be elaborated on further. Reasons for the company's distress should form part of the background analysis. Clear and concise reasons must be given as to why the business is in financial trouble. The practitioner should furthermore make a clear distinction between the symptoms and causes of distress. Often vague macro-environmental factors are blamed, 
without any mention of internal reasons, leading to further frustration and distrust in the plan by affected persons.

Part of the turnaround strategy is the actions already taken by the practitioner. The plan should list these events and explain how they contribute to the overall turnaround strategy. Implementation is a key component of the plan (Dolan, 1983:26); therefore, elaborating on these decisions and how they have been executed to date can contribute to the credibility of the strategy. Proper consultation in relation to how the plan will be executed is paramount to persuading decision makers (creditors) to vote for the plan.

\section{Feasibility Analysis}

The feasibility analysis (study) concerns itself with one of the key expectations of the plan: "Is there still a viable business?" (Pretorius, 2013b:21). All the subjects stressed this point in one form or another, emphasising repeatedly how important it was. The feasibility study is usually conducted prior to filing for business rescue by the practitioner. A viability analysis/due diligence of the company's affairs should be ideally conducted after filing, to ratify many of the assumptions made in the feasibility study. Critical success factors should be identified and coupled with possible risks. Defining the boundaries of feasibility is also important, to assist parties in knowing when to 'pull the plug'. The feasibility study was also expected to explore the competitive environment. Analysis of whether or not the opportunity for the company to exploit its market still exists usually remains unanswered. Subjects were also asked if there was room for an objective test for feasibility; however, the general consensus was that the industry was too young and that best practices should be established beforehand.

\section{The Turnaround Strategy}

Closely linked to the feasibility and viability of the company is the turnaround strategy. All the subjects recognised that it was vital to have a turnaround strategy presented in the plan. The turnaround strategy usually forms the bulk of 
the document, encompassing various sections used to substantiate and describe how the plan will unfold. One subject described it as follows: "The turnaround strategy needs to flow like a story". The task of engineering a strategy is by no means an easy one. Though subjects acknowledged this to be a mammoth task, they reiterated that the strategy must be backed by facts as much as possible. Synonymous with turnaround situations is the credibility of data (Pretorius \& Holtzhauzen, 2008:99), and as a consequence stakeholders require the strategy to be substantiated by a creditable source. Disclosing source documents and utilising external data such as bank statements and industry norms can be of great help. Industry benchmarking enables critical and objective evaluation of the strategy itself. In addition to this, practitioners should refer to past business turnaround models where possible. Interlinking it to past plans that have been successful would increase stakeholder confidence.

\section{Cash Flow Analysis}

Forecasted financials accompanying the strategy are usually the most scrutinised section. Subjects indicated that the business model, with all its assumptions and alternative scenarios, should in combination with the financials be stress tested and elaborated on as far as possible. The most important element identified was that of a cash-flow projection, despite its not being a requirement of section 150 of the act (Republic of South Africa, 2008). All subjects referred to the cash-flow statement as an integral part of their decision-making process. The importance of this component cannot be emphasised enough. The plan is expected to make 'cash-flow sense' to interested parties. The distressed environment is indicative of cash-flow constraints as well as obvious hurdles inhibiting rehabilitation. As a consequence, tailoring the cash-flow statement is necessary to reflect the harsh reality that awaits the company.

\section{Sensitivity Analysis}

To improve decision making, the cash-flow forecast should further incorporate alternative scenarios and be accompanied by a sensitivity analysis. A SWOT 
breakdown could identify critical resources supplemented by a risk assessment. Such critical components should be evaluated and incorporated in the sensitivity analysis in order to minimise the risk forgone by the sure monetary (rand) amount offered in liquidation. It is also important for any PCF funder's critical evaluation of the turnaround strategy.

\section{Business Rescue Legacy}

An aspect not often found in plans and yet one which the subjects deemed essential for securing long-term PCF is that of BR legacy. The term was identified and coined only after several interviews; however, the underlying concept was supported by all the subjects. The phrase refers to the negative sentiment and reputation left behind by the business rescue proceedings. The concept of formal rehabilitation is new to many South Africans (le Roux \& Duncan, 2013). Business rescue follows a debtor-friendly orientation, in contrast to a strong creditor-centred insolvency system. The culture of debt forgiveness is still fairly new, and as a result business rescue proceedings can have a negative effect on the company's reputation with suppliers, customers and staff. Acknowledging and implementing mechanisms to address reputation early in the strategy is expected and regarded essential for long term partners of the rescue.

\section{Leadership}

There is an unclear yet important expectation for the plan to address leadership. 'Leadership' has been chosen to describe this concept since the role might be held by the practitioner or new or existing management. Most notably are the roles and capabilities of the practitioner. Practitioners should use the plan to motivate and install confidence in their interim leadership position as the right person for the job.

In most plans the topic surrounding management is a contentious one, particularly where management or the directors of the company are believed to be part of the reason for distress. The practitioner is obliged to report any 
unlawful or careless conduct by the directors in terms of s141(c) of the act (2008). In addition, when creditors 'want blood' and feel management is to blame, pressure to disclose or clarify the situation becomes more pertinent. Where fraud or reckless trading is suspected of taking place, the issue should be addressed as to how the practitioner will expose it. The competencies and leadership of a company are a contentious matter, which the plan should not avoid. Furthermore, a succession plan should also be covered to clarify leadership roles after the practitioner and his or her team have left and substantial implementation has been achieved.

\section{Business rescue plan as a medium of communication}

It is stated under section 150(2) of the act that the plan must provide sufficient information for decision-making purposes. This then requires the plan to take the form of a decision-making document that can be effectively interpreted by all the affected parties in order for them to make fair judgment on the rescue process. The plan, if properly communicated, also offers a clear reference point amid the rapid and often confusing changes among multiple parties. Subjects reiterated that the plan should be a stand-alone document encompassing all the relevant information, but be the result of on-going communication with all the stakeholders throughout the drafting process. Figure 3 depicts the subjects' support for the different elements.

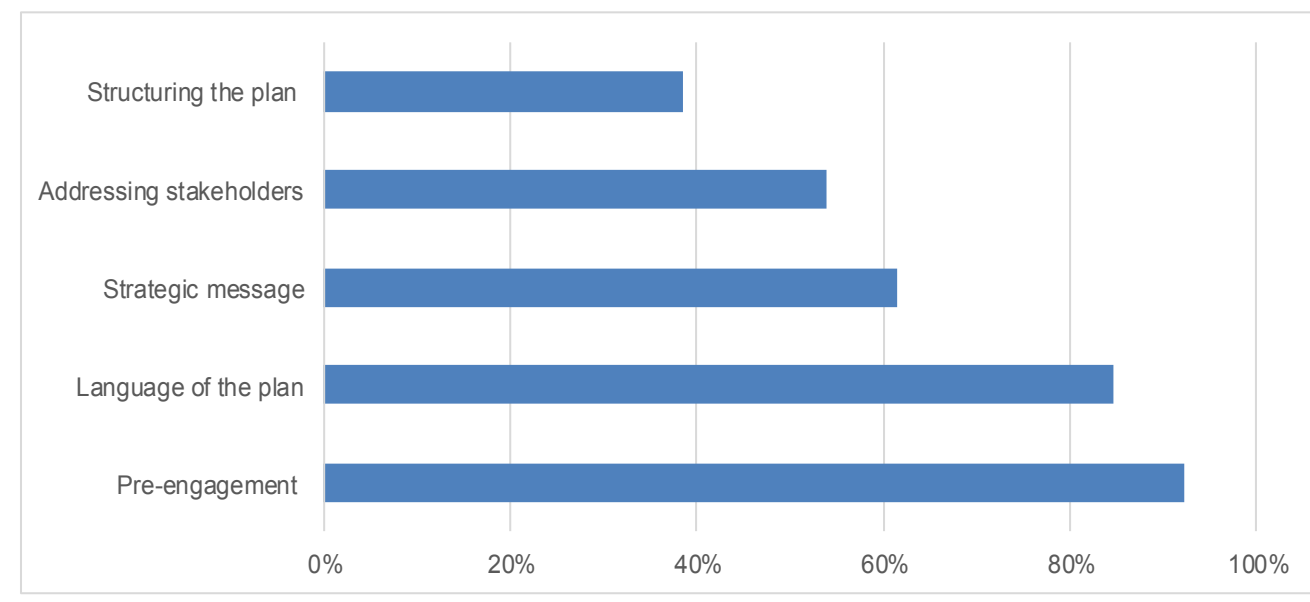

Figure 3 Relative support by subjects for elements associated with communication 


\section{Pre-engagement}

A key success factor identified by most subjects was that of pre-engagement with the affected parties, as critical to an effective and successful plan. Pretorius (2013b:21) also identified the importance of this element during proceedings. Assessing the knowledge and expectations of the affected parties beforehand assists the practitioner to identify the style, language and form to be used. Preengagement also allows the practitioner to manage expectations and educate stakeholders. At best, the plan should come with no surprises when published. The act allows for the formation of a creditors' committee to assist with this process.

\section{Language of the Plan}

As a decision-making document, subjects were asked what language proficiency was required to interpret the plan effectively. In many cases the plan is targeted at a multitude of parties with varying knowledge and language skills. Though acknowledging that this posed a dilemma, the subjects suggested that the plan's executive summary should cater for most readers and exclude any legal or financial jargon. The bulk of the plan, however, is expected to be a professional document requiring legal, financial or applicable knowledge in the relevant industry to interpret. However, legal or professional jargon should not be used to cloud the content, and a well-balanced knowledge of business should suffice at all times. Subjects in addition suggested the use of a terminology booklet to define and standardise business rescue terminology. This could be read in conjunction with the plan.

\section{Strategic Message}

At its core the plan is a sales document that must ultimately persuade its targeted audience of creditors to vote in favour of its proposed rescue strategy. As with any sales pitch, it is not just about what you say but also how you say it. Subjects agreed that it was unlikely that a 'dry' or clinical plan would fly when considering a business in severe distress. Convincing the readership requires emphasising 
key points and not getting bogged down in technicalities. Uncertainty does mist much of the proposal, as a number of estimations and assumptions are required. In all, however, the document should confirm a 'glimmer of hope' and confidence while delivering its message, as one of the subjects expressed it. The ambience of the plan can influence the sentiment behind its approval and implementation.

In some cases the plan may fall into the public domain. Currently it is unsure whether or not the plan is a public document; however, if this is so, those drafting it must consider its public exposure and the repercussions thereof. The media and external stakeholders could gain access to the document, making it vulnerable to misinterpretation and scrutiny by public opinion. Though this would have no impact on the voting procedure, it could contribute to the business rescue legacy discussed earlier. Furthermore, the opportunity should be taken to stifle rumours and address areas of concern. Practitioners should be cognisant of these and control them through remedies such as press releases and contact channels.

Though subjects supported the notion that the plan could entice and bolster support, they also warned against painting a 'blue sky'. Over-optimistic strategies were heavily criticised; these usually reduce confidence in the practitioner. The recommendation is then to propose a strategic but realistic message in order to protect the practitioner's reputation.

\section{Addressing Stakeholders}

The plan is statutorily obligated to address three affected parties: shareholders, creditors, and employees and the trade union representing them. The focus is generally on creditors, yet the plan is expected to also detail how both employees and shareholders will be affected. Where employees are concerned, the plan usually offers little insight into their role in the future. Mention of how change management and uncertainty will be dealt with can be greatly beneficial. Understanding the staff complement is key to the implementation of the strategy. 
It is unlikely that the volume and variety of creditors faced in a business rescue will allow a tailored response to the concerns of each in the plan. Creditors should not expect intricate details to be discussed unless they are deemed crucial to the overall strategy. However, subjects recommended that a disputeresolution mechanism should be in place, as well as clarification on claims for all the creditors involved. Consultation with creditors before publication is pertinent to attaining their insight and input, which would also lead to greater support.

A contentious issue was reported over whether the plan should accommodate an extended readership. Other than the three affected parties, the practitioner should consider additional stakeholders. All regulatory parties must be informed of proceedings (Republic of South Africa, 2008:s140(1)a); however, subjects questioned whether they should be addressed in the plan. Research data was unclear as to whether or not an extended readership should be considered, but subjects warned that this might distract from the purpose of the document. It was advised that stakeholders who play an integral role in the turnaround strategy should be mentioned. However, additional research is required to establish whether neglecting to mention external stakeholders, such as lobby groups, would have any detrimental effect on the rescue.

\section{Structuring the Plan}

How the plan is structured was of concern to a number of subjects. The document is expected to be professionally indexed and easy to read. Minutes of meetings should be attached, with all the relevant documentation. Detailed annexures are useful and allow for in-depth investigation. In some cases major institutions would be required to scrutinise the plan. Configuring sections in line with the organisational structure of large creditors could be helpful, as it would reduce the time taken to review the plan. 


\section{Business rescue plan as enabler of transparency}

All the subjects agreed that the plan is a tool for transparency and should disclose all the relevant information required for decision-making purposes. This entails detailing events leading up to the publication (history) of the plan and events planned to unfold after its approval. Information specified in the plan is provided to creditors and other interested parties to assist them to properly assess the plan. Under s150(2) of the act (2008), mandatory information must accompany the proposal, supported by appropriate mechanisms for obtaining it. The plan should satisfy the key objective of transparency and assist in ensuring creditor confidence in proceedings. A fair and balanced stance should always be maintained when confidentiality concerns arise from access to potentially sensitive financial and operational information relating to the debtor, even though that information may ultimately enter the public domain through approval or confirmation of the plan by a court. Figure 4 indicates the subjects' degree of support for each element.

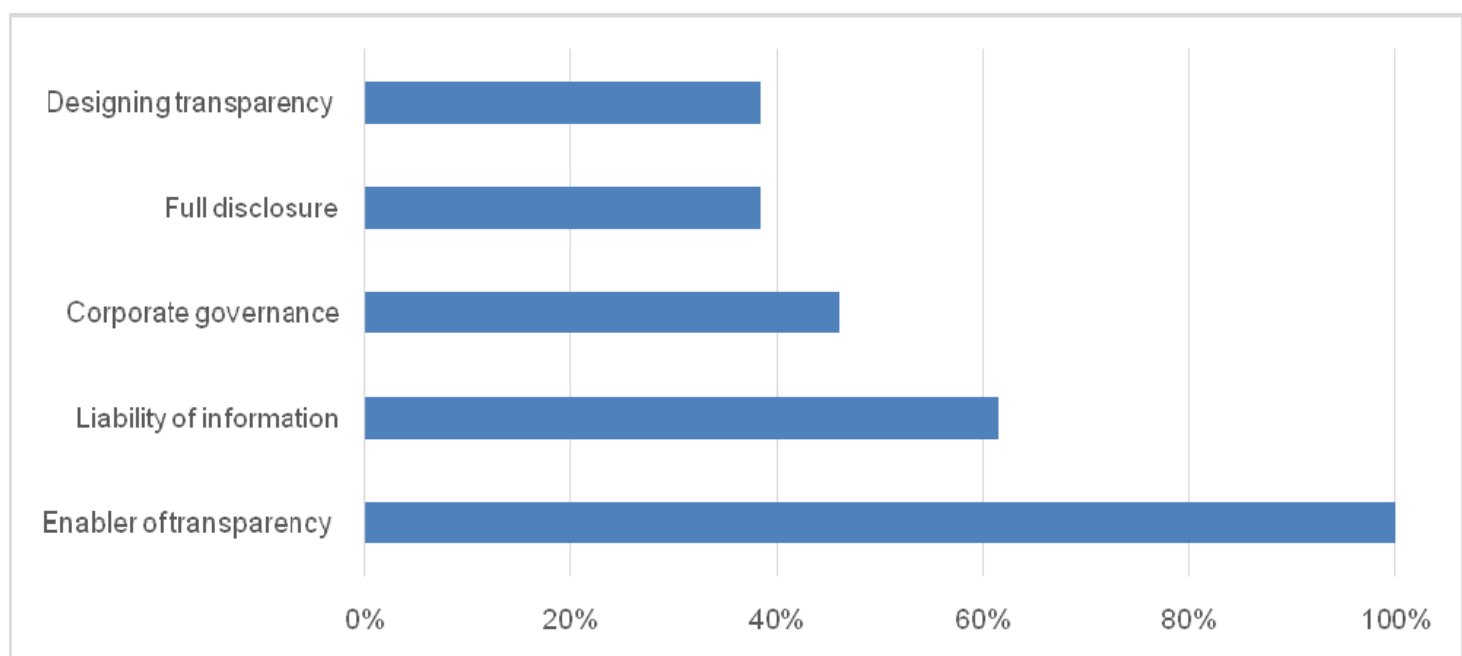

Figure 4 Relative support by subjects for elements that enable transparency. 


\section{Full Disclosure}

On a practical level, the plan cannot be expected to divulge unrelated information to affected parties. With a few exceptions, the majority of the subjects agreed that the practitioner had the discretion to withhold information where deemed appropriate. The capabilities of the practitioner are believed to be sufficient to make such judgements. Affected parties should request specific information prior to publication to assist the practitioner. Where information deemed relevant has been withheld, mention should be made of this, with substantiation and associated reasoning. It was clear from data obtained through the interviews that section 150(2) of the act would not automatically result in full disclosure and that in the majority of cases the plan would need to extend further to obtain compliance in terms of disclosure.

Where the plan enters the public domain, it may be less prone to discuss intricate details that might be considered detrimental to the rehabilitation of the company if disclosed. Other aspects such as reputational damage and the business rescue legacy might then be considered. However, its objective as a decision-making document is obstructed without adequate information. Where creditors and other parties do not believe that the disclosed information is convincing, their views should be acknowledged, allowing the plan as proposed to be amended or in the course of the confirmation process.

\section{Liability of Information}

The practitioner is obligated to conclude the plan with a certificate confirming that the information contained in the plan is accurate, complete and up to date (Republic of South Africa, 2008:s150(4)). Furthermore, estimates should be made in good faith on the basis of factual information and assumptions. Subjects reiterated that the practitioner remains ultimately responsible for the disclosure of information. The practitioner on appointment should be comfortable with facilitating a thorough, independent assessment of the business activities in order to engineer a plan accurate enough for affected parties to make a decision. 
The plan is also expected to expose any fraudulent activities or misappropriation by directors, or at least acknowledge that the matter is being dealt with. A growing concern of the subjects was that business rescue is being used to safeguard directors. This issue should be addressed, to avoid frustrating creditors and to maintain confidence in proceedings.

\section{Corporate Governance}

Synonymous with distressed ventures is a shortfall in corporate governance. Subjects were indecisive as to whether it played a role in the plan, indicating that though it was an important issue it might distract from the intended focal points. The view was that corporate governance should remain a 'golden thread' throughout the plan. But basic recovery methods should be the biggest concern, suggesting that "when you've saved them from drowning, then start giving them vitamins".

\section{Designing for Transparency}

The structure and language of the plan will affect transparency. Obscuring details with legal jargon or concealing them with heavily laden addenda will not suffice. The nature of the document must recognise and accommodate a dynamic audience which is required to yield a decision within a short period of time. Communication channels and timelines as to when and how information will be distributed on the plan's progress should be mentioned. The design of the plan is important to ensure information is effectively disclosed and understood.

\section{Business rescue plan as contractual obligation}

When the plan has been approved by the requisite majority of creditors and equity holders, it becomes a binding document on all the affected parties, including the practitioner. The contractual make-up of the plan offers a number of powerful remedies for the practitioner and the affected parties. The general sentiment among subjects was that this feature is not being utilised nearly as much as it should be, and that the contractual aspects of the plan are being 
neglected. The dynamic nature of the plan affords it the ability to legally bind key resources and secure ongoing support and responsibilities from individuals. Utilised correctly, contractual clauses can enforce areas of the turnaround strategy, thus giving it the necessary muscle to achieve completion. Figure 5 depicts the elements relevant for inclusion as contract elements.

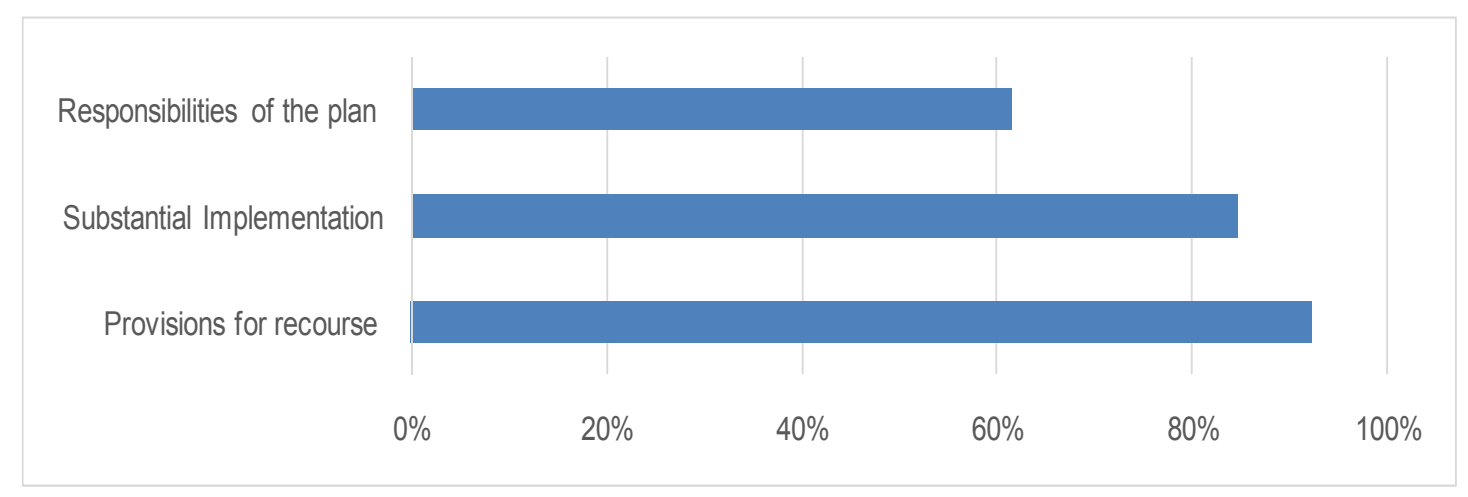

Figure 4 Relative support by subjects for elements that affirm the contractual obliqations of the plan

\section{Provisions for Recourse}

In the majority of cases the plan should be based on a number of reasonable assumptions. Detailing the assumptions, as well as the risks posed by them, offers insight into the feasibility of the plan and better mitigates liability concerns. The volatile nature of turnaround often requires alternative scenarios to be projected, against the possibility that key assumptions could fail. A prominent expectation that was identified was that scenario planning (options) was a definite requirement element in the plan. Contractually engineering a plan to adapt to various scenarios extends its effectiveness and possibility of success. It allows recourse, without defaulting on the primary strategy and consequently having to develop a new business rescue plan. Subjects indicated that where recourse beyond the alternative scenarios was required, the plan should then elaborate on procedures to be followed, such as renewed creditor meetings. 


\section{Substantial Implementation}

Another contractual aspect of the plan is to offer measurable milestones/objectives to be achieved, in order to facilitate ongoing communication and monitoring. Subjects stressed the need for performance indicators to be defined and communicated. Time-based reports, such as those requested by the regulator, should be mentioned, in addition to milestones linked to outputs such as payments. Components interlinking the feasibility study with the performance indicators could offer a grounded perspective as to whether or not the viability of the business still remains. Implementation should involve a 'gated' process.

The final objective that should be defined is substantial implementation. Subjects reiterated that this remains an elusive term used by practitioners, and should be explicitly defined. Scorecards also appear to be under-utilised in rescue plans. Clarifying 'substantial implementation' can reduce the liability on the practitioner. It also reduces the possibility of abuse. The practitioner's remuneration is directly linked to the duration of business rescue, offering an incentive to continue the process for longer than it should last.

\section{Responsibilities to the Plan}

Ultimately the plan requires the collaboration of parties to achieve its objective. The practitioner often plays only a facilitation role in its implementation. Key suppliers, partners and employees are often critical success factors in the proposed strategy. Using the plan for its contractual abilities can be of significant value. Subjects encouraged the plan to secure the support of key players, employing contractual subordination, clarifying relationships and detailing penalties for breach of contract. Where the plan is obligated to clarify any infringements on an affected party's rights, the party's responsibilities should accompany it. 


\section{Attract and secure post commencement funding}

In accordance with the research into PCF by Pretorius and Du Preez (2013), the consensus from subjects was that the plan is expected to include, in detail, all financing required from filing (day one of business rescue) until the closure of rescue proceedings. The plan, however, can detail either the working of a prearranged PFC deal or the attraction of PFC financing. The two alternatives are vastly different, as they influence the entire agenda of the document.

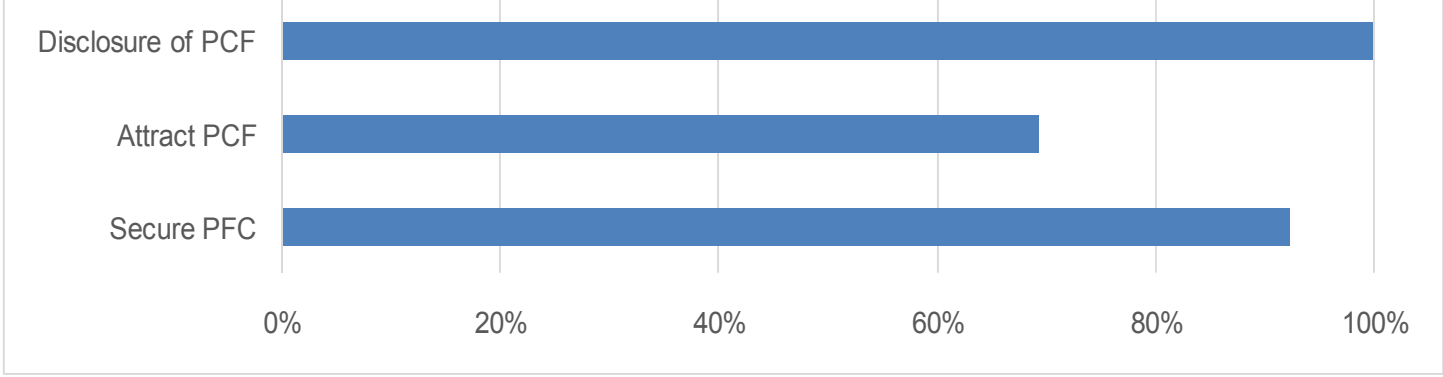

Figure 5 Relative support by subjects for elements of post commencement finance

\section{Locking in Secured PFC (Pre-vote)}

The plan is geared towards the presentation, and approval by creditors, of 'Post Plan' or Exit Finance (du Preez, 2012:93). Where PFC has been secured prepublication, it would be focused on gaining creditor support. The investor in such a case would form part of the plan's development and there would be no need to pitch an investor's agenda. It should rather be designed to sway creditor support for the PCF deal. Subjects expected such a proposal to contain detail workings of the deal, including the return on investment.

\section{Attracting New PCF (Post-vote)}

In the adverse scenario, where PCF has not been secured prior to the publication of the plan, the plan is expected to attract and secure a PFC deal. Subjects indicated that this would be the less favoured approach, as it requires a far more 
compelling argument to succeed. Confirmation should ensure the creditors' blessing for a financing tender, and be testament to their ongoing support. Data obtained also suggested that investor confidence relied heavily on proving longterm sustainability and detailed cash movements. Research (Pretorius \& Du Preez, 2013) has identified a number of key expectations from potential financers: the viability of the business, underlying business model, independent verification of data, sound and sustainable rescue plan, proper pre-assessment of the business and a thorough analysis of the rescue and liquidation scenario.

\section{Disclosure of PCF}

The disclosure of PCF deals was soundly supported by the majority of subjects, as indicated in Figure 5, emphasising that information pertaining to any PCF deal is critical to the assent to the plan. Supporting arguments held that any PCF deal has the ability to affect the feasibility and fairness attributed to the proposal. The impact of PCF transactions should be clear and the plan should detail the benefits or risks they pose to the rescue process. Should the plan seek approval prior to the conclusion of any PFC deal, it should stipulate conditions for the approval of any deal, or request that any PFC be brought back to a creditors' meeting for ratification.

\section{CONCLUSION}

Analyses of opposing expectations by subjects revealed that many of these were associated with what the plan aimed to achieve. Engineering the plan correctly is crucial to firmly aligning the correct expectations with a business rescue situation. Based on the expectations determined by subjects, detailed above, Figure 6 offers a perspective on how to approach and construct the plan to better serve the expectations of the required audience. 


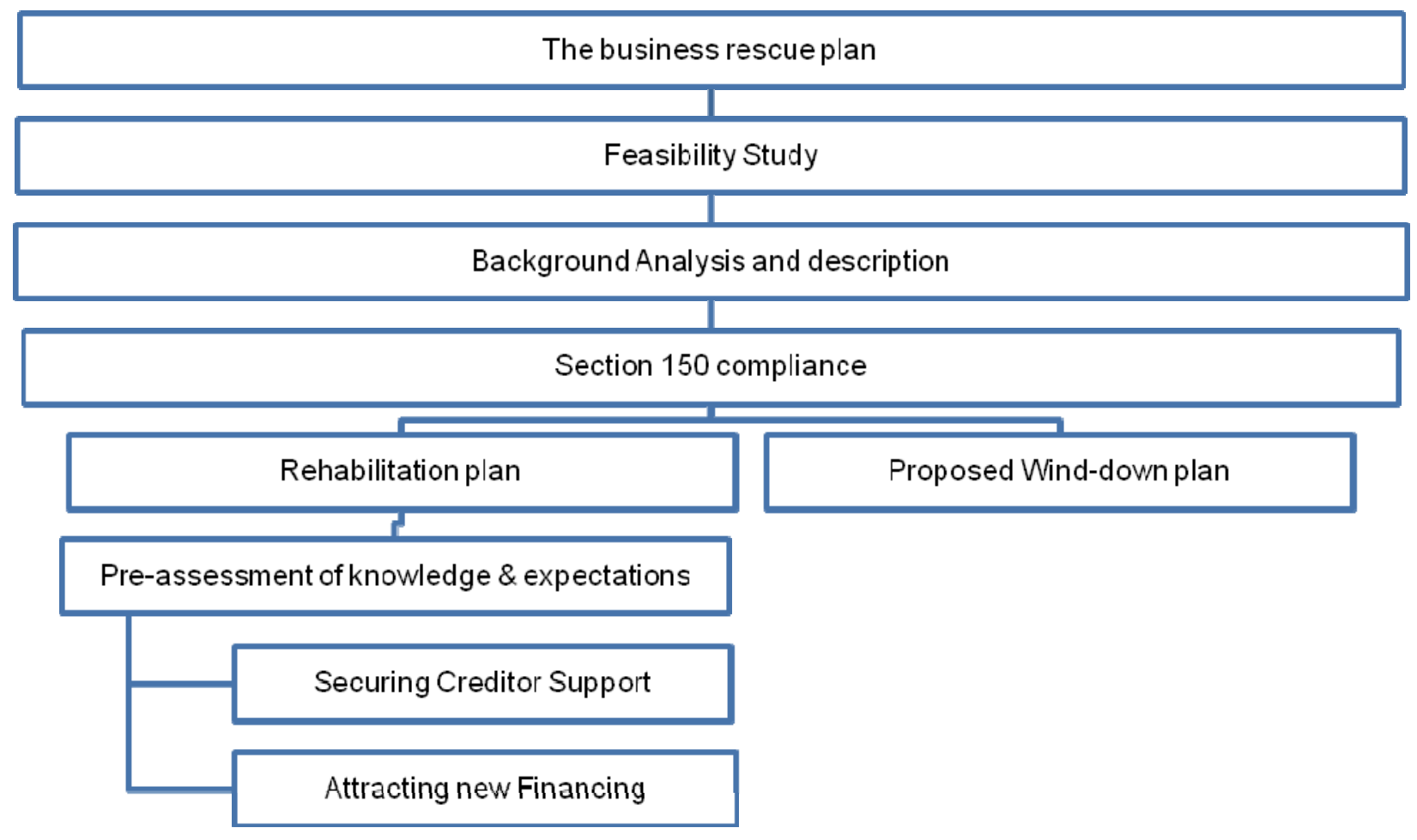

Figure 6 Approaching the plan

Determining the feasibility and viability of the entity is required before anything else. This step, though premature, constitutes the first phase of the plan. Following the feasibility analysis, the practitioner is tasked with the investigation of the affairs of the company (Republic of South Africa, 2008:s141), and so the background description is compiled. At this stage the bulk of information has been gathered and elements required in section 150(2) can be fulfilled. The result of the investigation thus far should point to a rehabilitation plan or a proposed wind-down, the two being distinctly different. If a proposed wind-down is chosen, the plan in its current form should suffice to meet the expectations of the affected parties. In the case of a rehabilitation plan, a pre-assessment of the affected parties' knowledge and resources should be determined in order to facilitate effective communication. If PCF is required, the plan is then fractured again in order to either seek funding or the support of the creditors. The expectations pertaining to the rehabilitation plan remain the basis of this study. 
The study was able to confirm that there is indeed a gap between the mandatory elements prescribed in section 150(2) and the provision of sufficient information to enable stakeholders to make a decision, as required by section 150(1) of the act. Opinions of the expert subjects confirmed that accepted international principles are applicable to the business rescue plan (Pretorius \& Rosslyn-Smith, 2014 forthcoming). The elements formulated in this study from stakeholder expectations of the business rescue plan offer insight and clarity in terms of what is expected of the plan. Where subjects held opposing views, consenting elements were engineered to better grasp the concept.

\section{CONTRIBUTION TO MANAGEMENT}

This research contributes to the management body of knowledge. Figure 6 in this study serves as a framework to guide business rescue plan development. It combines international guidelines with local expectations to formulate guidelines for compiling the plan. Affected persons, especially creditors, should benefit from this framework, as would practitioners in training.

\section{LIMITS OF THE STUDY AND SUGGESTED FUTURE RESEARCH}

The study was constrained by limited literature on the topic of business rescue, in particular on the rescue plan. At the time of the research, business rescue had only operated for approximately thirty months. These factors could possibly have limited the exploration and interpretation of the findings. Though subjects were requested to offer objective counsel, the risk of bias in view of their discipline or social desirability remains plausible (Saunders et al., 2009:326). The limitations and pitfalls of individual depth interviews recognised by Marshall and Rossman (2006:102) and by Ritchie and Lewis (2003:138) were acknowledged, and mitigated as far as possible. The researchers acknowledge that the number of subjects interviewed may hinder the study, even though data saturation was reached after eight interviews. Finally, the study relied heavily on the researchers' own interpretation, and therefore this is accepted as a plausible limitation. 
Business rescue remains relatively untouched in terms of academic literature and a number of its aspects require extensive investigation. The findings of this study have uncovered a number of opportunities for further research, in particular the direct impact of omitting expectations. Additionally, exploration into best practices in terms of the structure and presentation of information should be considered.

\section{REFERENCES}

Balgobin, R. \& Pandit, N. 2001. Stages in the turnaround process: The case of IBM UK. European Management Journal, 19(3):301-316.

Blumberg, B., Cooper, D. R. \& Schindler, P. S. 2008. Business research methods, New York, NY, McGraw-Hill Higher Education

Cooper, D. R. \& Schindler, P. S. 2008. Business research methods, New York, NY, McGraw-Hill Higher Education.

Dolan, P. F. 1983. A four-phased rescue plan for today's troubled companies. Journal of Business Strategy, 4(1):22-30.

Du Preez, W. 2012. The status of post-commencement finance for business rescue in South Africa. Johannesburg: Gordon Institute of Business Science.

Du Toit, L. 2012. Tax implications for business rescues in South African law. University of Pretoria.

Fossey, E., Harvey, C., McDermott, F. \& Davidson, L. 2002. Understanding and evaluating qualitative research*. Australian and New Zealand journal of psychiatry, 36(6):717-732.

Guest, G. 2006. How many interviews are enough?: An experiment with data saturation and variability. Field Methods, 18(1):59-82.

INSOL International 2000. Statement of principles for a global approach to multicreditor workouts, London, INSOL International.

Johnson, G. W. \& Meyerman, G. E. 2010. Insolvency systems in South Africa Johannesburg: United States Agency for International Development.

Kloppers, P. 1999. Judicial management -a corporate rescue mechanism in need of reform. Stellenbosch Law Review, 10:417-435. 
Kow, G. 2004. Turning around business performance: Part 1. Journal of Change Management, 4(3):229-246.

Le Roux, I. \& Duncan, K. 2013. The naked truth: Creditor understanding of business rescue: A small business perspective. Southern African Journal of Entrepreneurship and Small Business Management, 6(167):57-74.

Leedy, P. D. \& Ormrod, J. E. 2001. Practical research: Planning and design. 7th edition, Upper Saddle River, NJ, Merrill Prentice Hall.

Loubser, A. 2010. Some comparative aspects of corporate rescue in South African company law. Pretoria: University of South Africa.

Marshall, C. \& Rossman, G. B. 2006. Designing qualitative research, Thousand Oaks, CA, Sage.

Pretorius, M. 2013a. A competency framework for the business rescue practitioner profession. Acta Commercii

Pretorius, M. 2013b. Tasks and activities of the business rescue practitioner: $A$ strategy as practice approach. South African Business Review, 17(4):1-26.

Pretorius, M. \& Du Preez, W. 2013. Constraints on decision making regarding post-commencement finance in business rescue. Southern African Journal of Entrepreneurship and Small Business Management, 6:168-191.

Pretorius, M. \& Holtzhauzen, G. T. D. 2008. Critical variables of venture turnarounds: A liabilities approach. Southern African Business Review, 12(2):87107.

Pretorius, M. \& Rosslyn-Smith, W. 2014 forthcoming. Expectations for a business rescue plan: International directives for chapter 6 implementation. Southern African Business Review.

Republic of South Africa 2008. Companies Act 71 of 2008. Government Gazette No 32121 Volume 421. Pretoria: Government Printer

Ritchie, J. \& Lewis, J. 2003. Qualitative research practice: A guide for social science students and researchers, Thousand Oaks, CA, Sage.

Saunders, M. \& Lewis, P. 2012. Doing research in business and management, Harlow, Pearson Education. 
Saunders, M., Lewis, P. \& Thornhill, A. 2009. Research methods for business students, London, Financial Times/Prentice Hall.

United Nations. 2005. Legislative guide on insolvency law. Available from: http://www.uncitral.org/uncitral/en/uncitral texts/insolvency/2004Guide.html [Accessed 23 November 2013].

United Nations. 2012. Uncitral model law on cross-border insolvency with guide to enactment. Available from: http://www.uncitral.org/pdf/english/texts/insolven/V1188129Judicial Perspective ebook-E.pdf [Accessed 15 June 2013].

Westbrook, J. L. 2010. A global view of business insolvency systems, Washington, Martinus Nijhoff.

World Bank. 2005. World bank principles for effective creditor rights and insolvency systems. worldbank.org [Online]. Available from: http://www.worldbank.org/ifa/IPG\%20\%20Revised \%20Pples\%20FINAL\%20\%5B21\%20Dec\%202005\%5D.pdf [Accessed 21 December 2013].

Yin, R. K. 2003. Case study research: Design and methods, Thousand Oaks, CA, Sage. 